\title{
National Italian Delphi panel consensus: which measures are indicated to minimize pegylated-asparaginase associated toxicity during treatment of adult acute lymphoblastic leukemia?
}

Federico Lussana ${ }^{1 *}$ (I) Paola Minetto ${ }^{2,3}$, Felicetto Ferrara ${ }^{4}$, Sabina Chiaretti ${ }^{5}$, Giorgina Specchia ${ }^{6}$ and Renato Bassan ${ }^{7}$

\begin{abstract}
Background: L-asparaginase (L-ASP) is a key component of acute lymphoblastic leukemia (ALL) treatment, but its use in clinical practice raises challenges to clinicians due to a relatively high incidence of drug-related adverse events, mainly in adult patients. In the past years the use of ASP in adult population has been mainly limited due to a poor knowledge of its safety profile and to an approximate management of ASP-related toxicity. Recently the development of pediatric-inspired treatment protocols for adult ALL has led to a wider use of ASP and since 2010 in Italy three national treatment protocols including Pegylated asparaginase (Peg-ASP) have been sequentially developed for adolescents, young adults and adults with Philadelphia-negative (Ph-) ALL.

Methods: With the aim to better understand the approach adopted in Italian centers for the management and prevention of Peg-ASP toxicity in adult ALL and to provide practical, consensus-based recommendations, a board of 6 Italian clinicians, with known expertise in adult ALL, designed 41 consensus statements on current challenges on the management of Peg-ASP associated toxicity. A group of 19 clinical experts in the field then rated these statements using the 5 -point Likert-type scale ( 1 = strongly disagree; $5=$ strongly agree).

Results: The main Peg-ASP related issues identified by the board included: 1) clinician's attitudes; 2) toxicity profile; 3) hypersensitivity reactions; 4) hepatic toxicity; 5) hepatic and/or metabolic toxicity; 6) hemorrhagic/thrombotic toxicity; 7) pancreatitis; 8) metabolic toxicity management and prevention; 9) activity levels monitoring. Overall, participants agreed on most statements, except those addressing the potential contraindications to the treatment with Peg-ASP, such as patients with a diagnosis of chronic liver disease or the subsequent administrations of the drug in patients who had previously developed chemical pancreatitis or severe metabolic toxicity. Participants agreed that adult patients with ALL should receive Peg-Asp because this drug is essential to improve treatment results.

(Continued on next page)
\end{abstract}

* Correspondence: flussana@asst-pg23.it

'Hematology and Bone Marrow Transplant Unit, Azienda Socio Sanitaria

Territoriale Papa Giovanni XXIII, Piazza OMS, 1, 24127 Bergamo, Italy

Full list of author information is available at the end of the article

(c) The Author(s). 2020 Open Access This article is licensed under a Creative Commons Attribution 4.0 International License, which permits use, sharing, adaptation, distribution and reproduction in any medium or format, as long as you give appropriate credit to the original author(s) and the source, provide a link to the Creative Commons licence, and indicate if changes were made. The images or other third party material in this article are included in the article's Creative Commons licence, unless indicated otherwise in a credit line to the material. If material is not included in the article's Creative Commons licence and your intended use is not permitted by statutory regulation or exceeds the permitted use, you will need to obtain permission directly from the copyright holder. To view a copy of this licence, visit http://creativecommons.org/licenses/by/4.0/. The Creative Commons Public Domain Dedication waiver (http://creativecommons.org/publicdomain/zero/1.0/) applies to the data made available in this article, unless otherwise stated in a credit line to the data. 
(Continued from previous page)

Conclusions: The panel agreed that a critical evaluation of specific risk factors for each patient is crucial in order to reduce the risk of adverse events and specific advices in the management of Peg-ASP toxicities are reported.

Keywords: Pegylated asparaginase, Acute lymphoblastic leukemia, Toxicity

\section{Background}

L-asparaginase (L-ASP) is a key component of acute lymphoblastic leukemia (ALL) treatment both in childhood and adult setting [1-3]. Lymphoblastic leukemic cells do not express the enzyme asparagine synthetase, therefore are unable to produce asparagine de novo and depend on extracellular sources. The clinical effectiveness of L-ASP is based upon the depletion of circulating asparagine, since a sustained depletion of asparagine may lead to leukemic cell death [4]. Most of our knowledge about L-ASP activity and toxicity profile derives from the pediatric experience which has extensively incorporated L-ASP into ALL treatment protocols over the last 50 years [5]. On the contrary, the relatively higher incidence of drug-related adverse events in adult patients has limited its use in adults. Only in the last few decades the development of pediatric-inspired treatment protocols for adult ALL has led to a wider use of L-ASP in these patients, confirming its significant anti-leukemic activity also in the adult setting [6-8].

Pegylated asparaginase (Peg-ASP) gives the advantage of a more favorable pharmacokinetic and immunologic profile, that allows to achieve 2-3 weeks of serum enzymatic activity after a single drug administration and a significant reduction of L-ASP neutralizing antibodies development [9-13]. The toxicity profile of Peg-ASP has been proven to be similar to that of the native $E$. coli formulation and therefore in 2006 Peg-ASP has received FDA approval for the first-line treatment of ALL. However, in contrast to the pediatric setting, the optimal schedule and safety profile of Peg-ASP administration in the adult population have not yet been clearly established. Moreover, the longer half-life conferred by pegylation raises concerns about the management of a worrisome long-lasting toxicity during the back-ground chemotherapy schedule.

It is known that the risk of developing ASP-related toxicities is age-dependent with a proportional increase in incidence and severity. In addition, pharmacokinetic studies suggest that adolescent and adult ALL patients have a lower rate of ASP clearance [14, 15]. However, serum enzymatic activity monitoring has not been routinely performed and reliable pharmacokinetic data on the use of Peg-ASP in the adult population are lacking.

The most serious adverse effects associated with ASP in adult ALL patients are hepatotoxicity, pancreatitis, hyperglycemia and hypertriglyceridemia, thrombosis and alterations of the hemocoagulative parameters and hypersensitivity [16]. In this manuscript we refer to the main ASP-associated toxicities using the definition and grade of severity according to the Common Terminology Criteria for Adverse Events (CTCAE) version5.0 [17].

The development of severe toxicities can lead to significant delays in chemotherapy administration, impairing the efficacy of the whole antileukemic treatment and can be potentially life-threatening especially when associated with severe neutropenia and infectious complications [18]. All in all, it is mandatory to identify patients at high risk of developing high-grade ASP-related toxicities for an effective and homogeneous approach to the prevention and management of these toxicities in order to improve the safety and efficacy of ASP treatment in adult ALL. This is a very relevant clinical issue, because modern pediatric-inspired ASP-containing regimens yielded significantly better survival results than ASP-free regimens in Ph- ALL, at least in adolescent and young adults and up to an age of 55 years [19-21]. The most notable experience with Peg-ASP in adult ALL has been reported by the German study group [7]. In a recent update on 2019 total patients aged 15-55 years and treated in the 07/03 study, the use of Peg-ASP during induction/consolidation (7 total doses) led to progressively better results in the standard risk group, with a 5-year CR rate of 63 and 77\% using Peg-ASP at 500-1000 IU/ $\mathrm{m}^{2}$ (cohort $1, n=437$ ) or at $2000 \mathrm{IU} / \mathrm{m}^{2}$ (cohort $2, n=$ $300)$, respectively $(P=0.002)$ [22].

Based on this background and since three national treatment protocols including Peg-ASP have been sequentially developed from 2010 onwards in Italy for PhALL in adolescents and young adults (AYA, age range 18-35 years: Gruppo Italiano Malattie Ematologiche dell'Adulto (GIMEMA) LAL 1308) [23] and adult ALL (age range 18-65 years; GIMEMA LAL 2317 and LAL1913) $[24,25]$, the present work aimed to critically examine the approach adopted in Italian centers to manage PegASP toxicity in adult ALL and to provide practical, consensus-based recommendations from a national panel of ALL Experts.

\section{Methods}

\section{Literature revision and the Delphi method}

A group of six Italian clinicians (thereafter referred to as the board), with known interest and high skills in treating adult ALL, aimed at reaching a consensus on current 
challenges related to the management of Peg-ASP associated toxicity in adult patients with ALL, by adopting the Delphi method, a well-established methodology used in the scientific field [26-28]. After a careful review of the scientific literature, the board identified the following four topics currently lacking a clinical consensus and elaborated a Delphi questionnaire:

- Asparaginase use and formulation type in the different phases of ALL therapy in adults;

- Pediatric like approach;

- Peg-asparaginase-toxicity;

- Risk factors.

During a second phase, the questionnaire was validated by 10 external clinicians and then submitted to a panel of 19 additional Italian clinical experts in the field, through an online platform for a first Delphi round. The results of the questionnaire were then analysed by the board, which re-formulated the items that were not sufficiently well categorized during the first round $(n=2)$. For these two items a second Delphi round was performed using the revised version of items.

\section{Delphi questionnaire}

As reported in detail in the supplementary file 1, the Delphi questionnaire contained 9 statements, each containing three to six items: 1) clinician's attitudes on PegASP; 2) toxicity profile; 3) hypersensitivity reactions; 4) hepatic toxicity; 5) hepatic and/or metabolic toxicity; 6) haemorrhagic/thrombotic toxicity; 7) pancreatitis; 8) metabolic toxicity management and prevention; 9) activity profile monitoring. The 19 participating experts were invited to express their level of agreement or disagreement on each item using a Likert-type scale from 1 to 5 ( 1 = strongly disagree, $2=$ disagree, $3=$ somewhat agree, $4=$ agree, $5=$ strongly agree). Results were expressed as a percentage of respondents who scored each item as 1 or 2 (disagreement) or as 3,4 or 5 (agreement). Consensus was achieved when the sum for disagreement or agreement was $\geq 66 \%$ : affirmative consensus was defined in case of agreement $\geq 66 \%$, negative consensus in case of disagreement $\geq 66 \%$, while when the sum for disagreement or agreement was below $66 \%$ consensus was not reached.

\section{Results}

Among all items, 9 did not reach consensus, 29 reached a positive consensus and 3 achieved a negative consensus. The board decided to reformulate items 7.5 and 9.2 to improve clarity and avoid confusion in interpreting the questions by the expert panel. The revised version of item 7.5 reached an affirmative consensus, while item 9.2 did not reach any consensus. The Delphi process is outlined in Fig. 1. The final consensus for each item is summarized in Table 1.

\section{Consensus statements}

1. Clinical usefulness of E.coli Peg-ASP for the treatment of adult patients with Philadelphia negative acute lymphoblastic leukemia

1.1 Peg-ASP is a pivotal medication in the treatment of ALL, indispensable if the treatment aim is curative. Consensus result: $100 \%$ affirmative, median score 5 (range 3-5)

1.2 There are patients for whom there is an absolute contraindication to the use of Peg-ASP (age, comorbidity). Consensus result: consensus not reached, median score 3 (range 2-5)

1.3 The study of patient-associated risk factors may significantly limit the incidence of adverse events related to the use of Peg-ASP). Consensus result: $100 \%$ affirmative, median score 4 (range 3-5)

1.4 The toxicities associated with the administration of Peg-ASP are manageable in the majority of adult patients. Consensus result: 100\% affirmative, median score 4 (range 3-5)

2. Peg-asparaginase toxicity profile

2.1 It is difficult to predict and characterise the PegASP toxicity profile due to inter-patient significant variability (individual predisposition). Consensus result: consensus not reached, median score 3 (range 1-4)

2.2 It is needed an appropriate knowledge of the mechanisms underlying the development of toxicities in order to establish adequate preventive measures and early intervention at the onset of toxicity. Consensus result: 100\% affirmative, median score 4 (range 3-5)

2.3 Concomitant therapies (chemotherapy, antibiotics, antifungals, steroids) may potentially influence the toxicity profile. Consensus result: 95\% affirmative, median score 4 (range 2-5)

2.4 Fatal outcome on rare occasions. Consensus result: $100 \%$ affirmative, median score 4 (range 3-5)

\section{Hypersensitivity reactions}

3.1 It is advisable to pre-medicate with hydrocortisone $100 \mathrm{mg}$ intravenous (IV) every administration of Peg-ASP to reduce its incidence and/or severity. Consensus result: $74 \%$ affirmative consensus, median score 4 (range 2-5)

3.2 In case of known grade 3-4 allergic reaction, further administrations of Peg-ASP are contraindicated. Consensus result: $95 \%$ affirmative, median score 4 (range 2-5) 


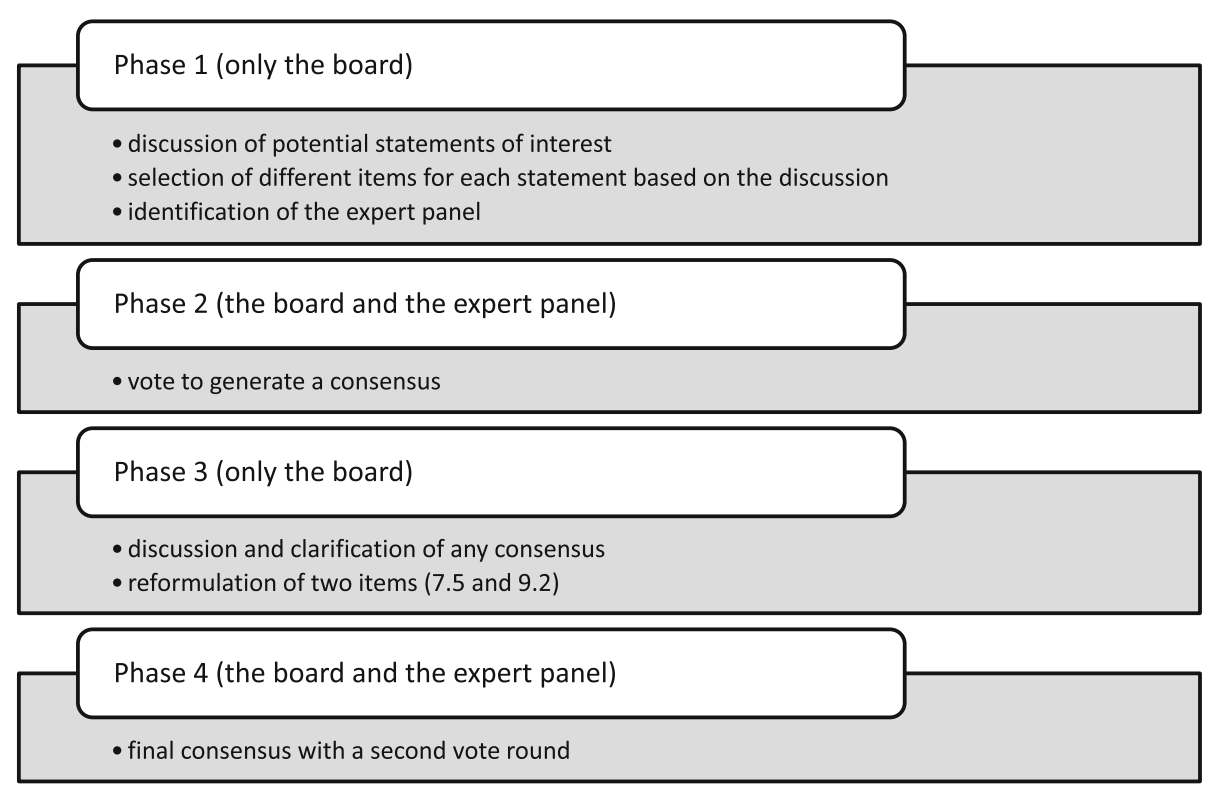

Fig. 1 Flow chart of Delphi process

3.3 In case of established grade 3-4 allergic reaction to Peg-ASP, substitution with the Erwinia chrysanthemi formulation is indicated. Consensus result: 95\% affirmative, median score 4 (range 2-5)

3.4 In case of a clinically manifested hypersensitivity reaction, ASP activity should be measured to promptly identify any possible inactivation of the medication. Consensus result: $74 \%$ affirmative consensus, median score 3 (range 2-5).

4. Hepatic toxicity

4.1 It is the most frequent toxicity and therefore requires close monitoring (pre-during-posttherapy). Consensus result: 95\% affirmative, median score 4 (range 2-5)

4.2 In addition to abdominal ultrasound, additional instrumental examinations are recommended prior to initiating Peg-ASP therapy. Consensus result: consensus not reached, median score 2 (range 1-5)

4.3 $\mathrm{BMI}>30$ and pre-existing hepatic steatosis contraindicate the use of Peg-ASP. Consensus result: $89 \%$ negative, median score 2 (range $1-3$ )

4.4 $\mathrm{BMI}>30$ and pre-existing hepatic steatosis require a reduction in the dosage of Peg-ASP. Consensus result: $89 \%$ affirmative, median score 4 (range 2-5)

4.5 Regardless of severity and degree of compensation, a diagnosis of chronic liver disease is an absolute contraindication of Peg-
ASP treatment. Consensus result: $74 \%$ negative, median score 2 (range $1-5$ )

4.6 Development of grade 3-4 toxicity does not contraindicate subsequent administrations of Peg-ASP. Consensus result: $68 \%$ affirmative, median score 3 (range $1-4$ )

5. Treatment of hepatic and/or metabolic toxicity

5.1 Concomitant therapy (chemotherapy, antibiotics, antifungals, steroids, other) plays a decisive role in increasing the risk of hepatotoxicity during Peg-ASP therapy. Consensus result: $95 \%$ affirmative consensus, median score 4 (range 2-5)

5.2 L-carnitine is recommended in the event of hyperbilirubinemia. Consensus result: $89 \%$ affirmative consensus, median score 4 (range 2-5)

5.3 Hyperglycemia should only be corrected with insulin therapy. Consensus result: $84 \%$ affirmative consensus, median score 4 (range 2-5)

5.4 Hypoalbuminemia should be corrected. Consensus result: $95 \%$ affirmative consensus, median score 4 (range $2-5$ )

6. Hemorrhagic/thrombotic toxicity

6.1 Laboratory alterations of the hemocoagulative parameters in the absence of clinical signs of thrombosis or bleeding do not necessitate discontinuation of Peg-ASP. Consensus result: $100 \%$ affirmative consensus, median score 5 (range 3-5) 
Table 1 Statements and results of the Delphi consensus process

\section{No Statement \\ 1. Clinical usefulness of E.coli Peg-ASP for the treatment of adult patients with Ph negative ALL}

1.1

1.2

1.3

1.4

\section{Peg-asparaginase toxicity profile}

\section{Hypersensitivity reactions}

\section{Hepatic toxicity}

4.1

\section{Treatment of hepatic and/or metabolic toxicity}

\section{Hemorrhagic/thrombotic toxicity}

Laboratory alterations of the hemocoagulative parameters in the absence of clinical signs of thrombosis or bleeding do not necessitate discontinuation of Peg-ASP haemorrhagic symptoms

Prophylaxis with LMWH is always recommended
Concomitant therapy (chemotherapy, antibiotics, antifungals, steroids, other) plays a decisive role in increasing the risk of hepatotoxicity during Peg-ASP therapy

$\mathrm{L}$-carnitine is recommended in the event of hyperbilirubinemia

Hyperglycaemia should only be corrected with insulin therapy

Hypoalbuminemia should be corrected
Any concomitant oral contraceptives or hormone replacement therapy should be discontinued
Consensus degree (\%)

$100 \%$ affirmative

Consensus not reached

100\% affirmative

100\% affirmative

Consensus not reached

100\% affirmative

95\% affirmative

100\% affirmative

74\% affirmative

95\% affirmative

95\% affirmative

74\% affirmative

95\% affirmative

Consensus not reached

89\% negative

89\% affirmative

74\% negative

68\% affirmative

95\% affirmative

89\% affirmative

$84 \%$ affirmative

95\% affirmative

100\% affirmative

89\% affirmative

consensus not reached

95\% affirmative 
Table 1 Statements and results of the Delphi consensus process (Continued)

\begin{tabular}{|c|c|c|}
\hline No & Statement & Consensus degree (\%) \\
\hline 6.5 & It is advisable to correct hypofibrinogenemia with cryoprecipitate & 79\% affirmative \\
\hline 6.6 & Replenishment of AT is advisable to maintain levels consistently above $60 \%$ & $100 \%$ affirmative \\
\hline \multicolumn{3}{|c|}{ 7. Peg asparaginase-associated pancreatitis } \\
\hline 7.1 & $\begin{array}{l}\text { Therapy should be discontinued if asymptomatic pancreatitis develops (CTCAE grade 2, i.e. } \\
\text { enzymes }>3 \text { times normal or radiological evidence) }\end{array}$ & Consensus not reached \\
\hline 7.2 & $\begin{array}{l}\text { The dosage should be reduced if asymptomatic pancreatitis develops (CTCAE grade 2, i.e. } \\
\text { enzymes }>3 \text { times normal or radiological evidence) }\end{array}$ & Consensus not reached \\
\hline 7.3 & $\begin{array}{l}\text { CTCAE grade } 2 \text { pancreatitis, once resolved, does not contraindicate subsequent administration } \\
\text { of Peg-ASP }\end{array}$ & 95\% affirmative \\
\hline 7.4 & $\begin{array}{l}\text { Development of CTCAE grade } 2 \text { pancreatitis contraindicates subsequent administrations even } \\
\text { with a different ASP formulation (Erwinia chrysanthemi) }\end{array}$ & $79 \%$ negative \\
\hline 7.5 & $\begin{array}{l}\text { Development of CTCAE grade 3-4 pancreatitis contraindicates subsequent administrations even } \\
\text { with a different ASP formulation (Erwinia chrysanthemi) }\end{array}$ & $95 \%$ affirmative \\
\hline \multicolumn{3}{|c|}{ 8. Metabolic toxicity management and prevention } \\
\hline 8.1 & $\begin{array}{l}\text { In the event of hyperglycemia with Peg-ASP and steroid therapy, it may be appropriate to re- } \\
\text { duce the steroid dose and enhance the insulin therapy rather than delay subsequent adminis- } \\
\text { trations of Peg-ASP }\end{array}$ & $100 \%$ affirmative \\
\hline 8.2 & Patients being treated should be monitored for triglycerides & 100\% affirmative \\
\hline 8.3 & $\begin{array}{l}\text { In case of severe (> } 500 \mathrm{mg} / \mathrm{dl} \text { ), persistent, isolated hypertriglyceridemia, it is advisable to delay } \\
\text { subsequent administrations of ASP }\end{array}$ & Consensus not reached \\
\hline 8.4 & $\begin{array}{l}\text { There is insufficient evidence that reducing the Peg-ASP dose reduces development of hepato- } \\
\text { pancreatic, thrombotic and metabolic toxicity }\end{array}$ & Consensus not reached \\
\hline 8.5 & $\begin{array}{l}\text { A preventive reduction in the dosage is always advisable if factors predisposing the } \\
\text { development of toxicity are identified (e.g. BMI }>30 \text {, hepatosteatosis) }\end{array}$ & $84 \%$ affirmative consensus \\
\hline \multicolumn{3}{|c|}{ 9. Monitoring of asparaginase plasmatic activity } \\
\hline 9.1 & $\begin{array}{l}\text { Monitoring of asparaginase plasmatic activity is essential in clinical practice in order to optimize the } \\
\text { therapeutic activity of asparaginase (e.g. change of formulation in case of drug inactivation) }\end{array}$ & $74 \%$ affirmative \\
\hline 9.2 & In clinical practice, routine monitoring of ASP plasmatic activity is useful in all patients with ALL & Consensus not reached \\
\hline 9.3 & $\begin{array}{l}\text { Searching for anti-asparaginase antibodies is of questionable value and should not therefore be } \\
\text { routinely performed outside research studies in adult ALL }\end{array}$ & 74\% affirmative \\
\hline
\end{tabular}

6.2 The use of fresh plasma to correct hypofibrinogenemia is not recommended in the absence of haemorrhagic symptoms. Consensus result: $89 \%$ affirmative consensus, median score 4 (range 2-5)

6.3 Prophylaxis with low molecular weight heparin (LMWH) is always recommended. Consensus result: consensus not reached, median score 3 (range 1-5)

6.4 Any concomitant oral contraceptives or hormone replacement therapy should be discontinued. Consensus result: 95\% affirmative, median score 4 (range $2-5$ )

6.5 It is advisable to correct hypofibrinogenemia with cryoprecipitate. Consensus result: $79 \%$ affirmative, median score 4 (range 2-5)

6.6 Replenishment of antithrombin (AT) is advisable to maintain levels consistently above $60 \%$. Consensus result: $100 \%$ affirmative consensus, median score 5 (range 3-5)
7. Peg asparaginase-associated pancreatitis

7.1 Therapy should be discontinued if asymptomatic pancreatitis develops (CTCAE grade 2, i.e. enzymes $>3$ times normal or radiological evidence). Consensus result: consensus not reached, median score 2 (range 1-5)

7.2 The dosage should be reduced if asymptomatic pancreatitis develops (CTCAE grade 2, i.e. enzymes $>3$ times normal or radiological evidence). Consensus result: consensus not reached, median score 3 (range 1-5)

7.3 CTCAE grade 2 pancreatitis, once resolved, does not contraindicate subsequent administration of Peg-ASP. Consensus result: 95\% affirmative consensus, median score 4 (range 2-5)

7.4 Development of CTCAE grade 2 pancreatitis contraindicates subsequent administrations even with a different ASP formulation (Erwinia chrysanthemi). Consensus result: 
$79 \%$ negative consensus, median score 2 (range 1-3)

7.5 Development of CTCAE grade 3-4 pancreatitis contraindicates subsequent administrations even with a different ASP formulation (Erwinia chrysanthemi). Consensus result: $95 \%$ consensus, median score 4 (range 2-5)

8. Metabolic toxicity management and prevention

8.1 In the event of hyperglycemia with Peg-ASP and steroid therapy, it may be appropriate to reduce the steroid dose and enhance the insulin therapy rather than delay subsequent administrations of Peg-ASP. Consensus result: 100\% affirmative, median score 4 (range $3-5$ )

8.2 Patients being treated should be monitored for triglycerides. Consensus result: $100 \%$ affirmative, median score 4 (range $3-5$ )

8.3 In case of severe (>500 $\mathrm{mg} / \mathrm{dl})$, persistent, isolated hypertriglyceridemia, it is advisable to delay subsequent administrations of ASP. Consensus result: consensus not reached, median score 3 (range $1-5$ )

8.4 There is insufficient evidence that reducing the Peg-ASP dose reduces development of hepatopancreatic, thrombotic and metabolic toxicity. Consensus result: consensus not reached, median score 3 (range 1-4)

8.5 A preventive reduction in the dosage is always advisable if factors predisposing the development of toxicity are identified (e.g. BMI $>30$, hepatosteatosis). Consensus result: $84 \%$ affirmative consensus, median score 4 (range 25)

9. Monitoring of asparaginase plasmatic activity

9.1 Monitoring of asparaginase plasmatic activity is essential in clinical practice in order to optimize the therapeutic effects of asparaginase (e.g. change of formulation in case of drug inactivation). Consensus result: $74 \%$ affirmative consensus, median score 3 (range 2-5)

9.2 In clinical practice, routine monitoring of ASP plasmatic activity is useful in all patients with ALL. Consensus result: consensus not reached, median score 3 (range 2-4)

9.3 Searching for anti-asparaginase antibodies is of questionable value and should not therefore be routinely performed outside research studies in adult ALL. Consensus result: $74 \%$ affirmative consensus, median score 3 (range $1-5$ )

\section{Discussion}

The complete consensus on the need of using Peg-ASP in the treatment of ALL reflects the fact that this drug is considered essential to improve treatment results. In this regard, in childhood ALL several trials have clearly demonstrated the benefits from intensified ASP therapy [29-32] and also in adult patients there is an increasing evidence of an improved result in ASP-treated vs noASP-treated patients [6, 33-35], as exemplified in the large German Multicenter Study Group for Adult (GMALL) 07/2003 study [7]. Overall, in this study, PegASP intensification resulted feasible in the majority of patients although a higher incidence of severe hepatic toxicity was reported.

In contrast, uncertainty remains over the absolute contraindication to the treatment with Peg-ASP. Participants agreed that special attention is required to identify patients with significant risk factors of toxicity that may outweigh the benefit of treatment.

There was consensus that hepatic toxicity is the most common complication in adult patients receiving PegASP [36]. Clinicians agreed that in the presence of BMI $>30$ and pre-existing hepatic steatosis a reduction of Peg-ASP dosage is required. Higher age, obesity (body mass index $[\mathrm{BMI}]>30$ ) are indeed established risk factors for the development of severe hepatic toxicity) [36, 37]. Acute onset of hepatic steatosis (with anatomopathological features of micro-vesicular steatosis) is a common consequence of ASP treatment [38, 39], so preexisting hepatic steatosis should be considered a warning for the development of ASP-related hepatic toxicity. As a general rule, a diagnosis of chronic liver disease does not represent an absolute contraindication for Peg-ASP treatment, but in these patients the board suggested to consider the use of Peg-ASP on an individual basis and after careful evaluation of its clinical severity. In case of hepatic toxicity, also up to grade 3-4, occurring during treatment with Peg-ASP, subsequent administrations are still indicated after delaying the treatment until AST/ ALT levels and bilirubin are within 5xULN and 3xULN ranges, respectively [40]. An example on how Peg-ASP treatment could be modulated based on the severity of the toxicity pattern and on the number of previous exposures is the algorithm currently adopted in the ongoing GIMEMA LAL 2317 trial [24]. Although this approach is not yet validated by clinical results, it represents a first attempt to introduce a risk- and ageoriented Peg-ASP dosing in an induction/consolidation multi-agent protocol carrying substantial risks of hematological and extra-hematological toxicity. A near complete consensus was obtained on the fact that concomitant therapies play a major role in determining hepatotoxicity during treatment with Peg-ASP. Therefore, preventive treatment strategies to decrease hepatotoxicity should include avoiding or adjusting the concurrent use of hepatotoxic drugs, including azol antifungal and antibiotics [40]. In addition, in the future protocols a careful spacing in terms of days before the use of other 
hepatotoxic antileukemic agents (anthracyclines, corticosteroids, cyclophosphamide and antimetabolites) should be taken into account.

There was consensus that, although Peg-ASP results in less immunogenicity than the native compound [9], premedication of each Peg-ASP dose with hydrocortisone $100 \mathrm{mg}$ IV is an essential step in order to reduce the likelihood and/or severity of acute hypersensitivity reaction. This consensus is in keeping with suggestions provided by an international expert panel [40]. Almost all clinicians who responded to the survey agreed that in case of serious allergic reactions (grade 3-4 according to National Cancer Institute (NCI) CTCAE) permanent discontinuation of Peg-ASP is indicated. Peg-ASP displays cross-reactivity with native $E$. coli ASP and allergic reactions are often also associated with an inactivation of the drug due to the development of ASP antibodies $[11-13,30]$. In this regard, clinicians indicated that in patients with serious allergic reaction a substitution with the Erwinia chrysantemi formulation is a preferable alternative to reduce the risk of subsequent allergic reactions and to ensure continued depletion of asparagine. Indeed, crisantaspase does not display cross-reactivity to either of the E. coli-derived products [41]. A weaker consensus was reached by the panel on the need of serum ASP activity level assessment in order to recognize a suboptimal enzyme activity, generally due to the formation of neutralizing antibodies, in patients with allergic reaction. This uncertainty reflects the logistic limitations in measuring ASP activity levels [42, 43] which made this strategy impractical for a broad clinical use in past Italian trials. Currently monitoring of ASP activity is available on request within the GIMEMA study ALL2518 [44].

The use of ASP is associated with reduced insulin production and possibly a decrease in the expression of insulin receptors $[45,46]$. In addition, corticosteroids cause insulin resistance. Therefore, hyperglycemia is quite common during phases of therapy with concomitant use of Peg-ASP and corticosteroids. Clinicians of the panel believe that safe management of hyperglycemia requires only the use of insulin. The use of oral hypoglycemic drugs should be avoided because they may increase the risk of hepatotoxicity.

In case of hyperbilirubinemia the use of L-carnitine is recommended as suggested in some reports [47-49]. A suggested L-carnitine schedule is $50 \mathrm{mg} / \mathrm{kg}$ daily intravenously in divided doses for 5-8 days until toxicity resolves. Addition of vitamin B complexes may also be helpful. Finally, hypo-albumin should be corrected by infusion of serum albumin, with the aim to maintain albumin levels $\geq 2.5 \mathrm{~g} / \mathrm{dl}$, in order to prevent peripheral edema and/or the more severe condition of anasarca. Maintaining a good albumin level is also essential to provide an adequate carrier mechanism to several antibacterial agents employed in case of neutropenic infectious complications. Of note, in the absence of studies that directly examine the benefit of correcting hypoalbuminemia, this suggestion derives from the formal consent of the expert panel.

The panel agrees not to withhold treatment for abnormal coagulation tests without clinical correlates. Although the benefit of correcting hypofibrinogenemia in terms of preventing hemorrhagic complications is unclear both in pediatric and adult setting [50,51], the expert panel considered cost-effective to correct hypofibrinogenemia with the use of cryoprecipitate. A consensus was reached against the use of fresh frozen plasma (FFP) since FFP may replete serum asparagine counteracting the anti-leukemic effect of ASP. In addition, the use of fibrinogen concentrates should be avoided in the absence of haemorrhagic symptoms since they may increase the risk of thrombosis [51].

A complete consensus on the need of antithrombin infusion if antithrombin level $<60 \%$ was obtained. This reflects the hypothetical linking between ASP-induced antithrombin deficiency and the risk of developing thrombotic events [52]. In this regard, a meta-analysis of 17 studies focusing on thrombotic complications in children with ALL found that the overall incidence of thrombosis is $5.2 \%$ and that slightly more than the $50 \%$ of the events occurred in the central nervous system (CNS), and $28.6 \%$ of the total events were classified as cerebral venous thrombosis [53]. Considering the higher risk of thrombotic events associated with the use of female hormones [54, 55] and the above-mentioned risk of thrombosis related to ASP-induced antithrombin deficiency, the panel suggested to avoid any concomitant hormonal therapies during treatment with Peg-ASP. The impact of heparin prophylaxis remains controversial [51, 56]. The results of a randomized study in the pediatric setting showed that prophylactic use of enoxaparin significantly reduced thromboembolism during induction therapy [56]. In contrast a very recent observational study in the adults setting by the French group GRAALL showed that the use of heparin prophylaxis was associated with a surprisingly increased risk of thrombosis [51]. In this context of uncertainty, a consensus was not reached about the use of primary antithrombotic prophylaxis with $\mathrm{LMWH}$, that mainly reflects the perception of a concomitant high bleeding risk for these patients, both due to a decrease in the production of proteins involved in coagulation associated with ASP use and to the relevant thrombocytopenia, usually observed during induction and consolidation cycles.

Some discrepancies exist concerning the use of PegASP in patients with chemical pancreatitis (e.g. elevation of amylase and/or lipase). The recommendations of an 
international expert panel reported to continue Peg-ASP treatment [40], considering that this form of toxicity is usually not life-threatening and resolves without longterm sequelae $[57,58]$. In patients with grade 2 pancreatitis, daily monitoring of enzymes is required and the drug should be withheld until amylase and lipase levels are below 3 times the upper limit of normal (ULN), in the absence of clinical symptoms [40]. There was a near complete consensus that in case of grade $\geq 3$ pancreatitis subsequent administration of ASP is contraindicated. Since the formulation of L-ASP does not influence the incidence of pancreatitis [59], the use of a different formulation (Erwinia chrysanthemi) is also contraindicated.

There is uncertainty if a transient discontinuation of Peg-ASP is appropriate in patients developing isolated severe hypertriglyceridemia $(\geq 500 \mathrm{mg} / \mathrm{dl}$ ). A recent study showed that a transient elevation in triglyceride levels of grade 3/4 was seen in about $47 \%$ of patients receiving ASP and corticosteroids and it is usually asymptomatic [60]. These patients should be closely monitored for signs of pancreatitis $[60,61]$, while there is not currently a specific treatment for hypertriglyceridemia. Hypertriglyceridemia is generally temporary and levels return to normal completely after Peg-ASP treatment is concluded [60]. In the rare cases displaying very high levels of triglycerides (i.e. $\geq$ $2000 \mathrm{mg} / \mathrm{dL}$ ) a temporary discontinuation of Peg-Asp may be prudential. Hyperidratation and omega-3 fatty acids supplementation can accelerate the restoration of normal triglycerides levels. Based on the abovementioned data, clinicians agreed that checking triglycerides levels in patients receiving Peg-ASP is useful, so that patients with severe hypertriglyceridemia at higher risk of developing pancreatitis or for whom a temporary discontinuation of treatment might be indicated are more easily identified.

There is an increasing agreement that monitoring of plasma ASP activity may be relevant in clinical practice in order to ascertain adequate ASP efficacy, since plasma activity levels $>=0.1 \mathrm{IU} / \mathrm{ml}$ correspond to a profound asparagine depletion and to an adequate therapeutic effect [11, 30, 62]. Another relevant advantage of measuring plasma ASP activity levels is the possibility to optimize the therapeutic effects of ASP (e.g. change formulation in case of inactivation of the drug) [63]. A consensus was not reached about the use of routine monitoring of ASP activity in clinical practice. However, its use should be considered for screening selected patients with overt or even doubtful signs of hypersensitivity [11, 43]. Indeed, this information may be of great value in clinical decision-making of switching to a different ASP preparation to ensure continuous plasma depletion of asparagine [12, 13, 63, 64]. Screening patients for neutralizing anti-asparaginase antibodies has been suggested in some reports, but the specificity of anti-asparaginase antibodies to predict inactivation has been found to be low compared with measuring ASP activity itself [43]. The measurement of asparaginase activity $(>0.1 \mathrm{IU} / \mathrm{ml})$ remains the most direct and convincing assessment of asparaginase effectiveness. In this regard, most recent data should be taken into account. In a pediatric study using a more sensitive technique, an effective serum asparagine depletion was obtained with an enzymatic activity as low as $0.02 \mathrm{IU} / \mathrm{ml}$ [65]; also, in adult patients, $80-90 \%$ of the cases receiving Peg-ASP $500-1000 \mathrm{IU} / \mathrm{m}^{2}$ reached drug levels $>0.1 \mathrm{IU} / \mathrm{ml}$, that persisted for 14 days in $77 \%$ with $1000 \mathrm{IU} / \mathrm{m}^{2}$ and for 7 days in $59 \%$ with $500 \mathrm{IU} / \mathrm{m}^{2}$ [66]. Finally, a recent study reported that adults with comorbidities receiving a reduced dose of PEG-ASP $<1000 \mathrm{IU} / \mathrm{m}^{2}$ experienced fewer toxicities while still attaining therapeutic activity levels $>0.1 \mathrm{IU} /$ $\mathrm{mL}$ [67]. The final consensus of the panel against the utility of routinely searching anti-asparaginase antibodies reflects the data mentioned above.

\section{Conclusions}

The development of pediatric-inspired treatment protocols for adult ALL has led to an increasing use of PegAsp in adults. The relatively high incidence of drugrelated adverse events has prompted a need for suggestions in the management and prevention of toxicities. The most serious adverse effects associated with ASP in adult ALL patients are hepatotoxicity, pancreatitis, hyperglycemia and hypertriglyceridemia, thrombosis, alterations of the hemocoagulative parameters and hypersensitivity. Here we reported the results of a Delphi consensus by a group of Italian experts in treating adult ALL that highlights the importance of a careful monitoring of drug toxicity and a correct evaluation of risk factors for each patient in order to reduce the risk of adverse events. Similar to the empirical guidelines provided in the most recent GIMEMA trial [24], the experts suggested that PegAsp schedule and dosing should take into account patient's age, body mass index and liver steatosis and whether or not grade 3-4 drug toxicity during first or prior Peg-ASP exposure has been observed. Coagulopathy (antithrombin and/or fibrinogen deficiency) can be prevented by the periodic infusion of antithrombin and cryoprecipitate as needed. The use of L-carnitine should be considered in patients with severe liver injury with direct bilirubin $>3 \mathrm{mg} / \mathrm{d} / \mathrm{L}$. Finally, although Peg-ASP results in less immunogenicity than the native compound, pre-medication of each Peg-ASP dose with hydrocortisone $100 \mathrm{mg}$ IV is advisable in order to reduce the likelihood and/or severity of acute hypersensitivity reaction. Moreover, therapeutic dose monitoring of Asp activity levels should 
Table 2 Summary of the main advices from Delphi questionnaire in the management of Peg-ASP toxicity

\section{No Prevention and Management}

\section{Hypersensitivity reactions}

It is advisable to pre-medicate every administration of Peg-ASP to reduce incidence and/or severity of hypersensitivity reactions

In case of known grade 3-4 allergic reaction, further administrations of Peg-ASP are contraindicated and substitution with the Erwinia chrysanthemi formulation is indicated

In case of a clinically manifested hypersensitivity reaction, ASP activity should be measured to promptly identify any possible inactivation of the medication

\section{Hepatic toxicity}

$\mathrm{BMI}>30$ and pre-existing hepatic steatosis require a reduction in the dosage of Peg-ASP

Development of grade 3-4 toxicity does not contraindicate subsequent administrations of Peg-ASP when grade toxicity $\leq 2$

L-carnitine is suggested in the event of hyperbilirubinemia

Concomitant therapy (chemotherapy, antibiotics, antifungals, steroids, other) plays a decisive role in increasing the risk of hepatotoxicity during Peg-ASP therapy

\section{Metabolic toxicity}

Hyperglycaemia should be corrected with insulin therapy and it is not an indication to discontinue or delay subsequent PegAsp administrations

Hypoalbuminemia should be corrected

\section{Hemorrhagic/thrombotic toxicity}

Laboratory alterations of the hemocoagulative parameters in the absence of clinical signs of thrombosis or bleeding do not necessitate discontinuation or delay of Peg-ASP

It is advisable to correct hypofibrinogenemia with cryoprecipitate

Replenishment of AT is advisable to maintain levels consistently above $60 \%$

\section{Peg asparaginase-associated pancreatitis}

CTCAE grade 2 asymptomatic pancreatitis, once resolved, does not contraindicate subsequent administration of Peg-ASP

Development of symptomatic pancreatitis or asymptomatic with CTCAE grade 3-4 amylase/lipase elevation contraindicates subsequent administrations even with a different ASP formulation

be implemented to identify patients with suboptimal activity levels to adjust treatment accordingly. A summary of the main advices in the management of Peg-ASP toxicity are reported in Table 2.

\section{Supplementary information}

Supplementary information accompanies this paper at https://doi.org/10 1186/s12885-020-07461-5.

Additional file 1:. List of involved experts

Additional file 2:. Delphi questionnaire.

\section{Abbreviations}

ALT: Alanine aminotransferase; apt: Activated partial thromboplastin time: AST: Aspartate aminotransferase; AYA: Adolescents and young adults; ASP: Asparaginase; ALL: Acute lymphoblastic leukemia; BMI: Body mass index; CNS: Central nervous system; CTCAE: Common Terminology Criteria for Adverse Events; FDA: Food and drug administration; FFP: Fresh frozen plasma; GMALL: German Multicenter Study Group for Adult; GIME MA: Gruppo Italiano Malattie Ematologiche dell'Adulto; INR: International normalized ratio; IV: Intravenous; IU: International unit; LLN: Lower limit of normal; LMWH: Low molecular weight heparin; MI: Milliliter; NCl: National Cancer Institute; Peg-ASP: Pegylated asparaginase; Ph-: Philadelphia-negative; ULN: Upper limit of normal

\section{Authors' contributions}

F.L. and P.M. elaborated the Delphi questionnaire, analysed the results of the questionnaire, wrote the text and gave final approval before manuscript submission. F.F., S.C. and G.S. elaborated the Delphi questionnaire, analysed the results of the questionnaire, revised the manuscript and gave the final approval before manuscript submission. R.B. elaborated the Delphi questionnaire, analysed the results of the questionnaire, provided major intellectual contributions to the preparation of the manuscript and gave final approval before manuscript submission. All authors have read and approved the manuscript.

\section{Funding}

No funding was received.

Availability of data and materials

The dataset used and analysed during the current study is available from the corresponding author on reasonable request.

\section{Ethics approval and consent to participate}

Not applicable. Ethics approval was not needed since this manuscript does not report on or involve the use of any animal or human data or tissue. The Venice Ethics Committee confirmed that no formal ethics approval was required according to the Italian national guidelines (DM 8/2/2013 and DGRV n' 1066 28/6/2013).

Consent for publication

Not applicable.

Competing interests

The authors declare that they have no competing interests. 


\section{Author details}

${ }^{1}$ Hematology and Bone Marrow Transplant Unit, Azienda Socio Sanitaria Territoriale Papa Giovanni XXIII, Piazza OMS, 1, 24127 Bergamo, Italy. ${ }^{2}$ Clinic of Hematology, Department of Internal Medicine (DiMI), University of Genoa, Genova, Italy. ${ }^{3}$ RCCS, Ospedale Policlinico San Martino, Genova, Italy. ${ }^{4}$ Division of Hematology, Cardarelli Hospital, Naples, Italy. ${ }^{5}$ Hematology, Department of Translational and Precision Medicine, Sapienza University, Rome, Italy. ${ }^{6}$ Department of Emergency and Organ Transplantation (D.E.T.O.), Hematology Section, University of Bari, Bari, Italy. ${ }^{7}$ Complex Operative Unit of Haematology, dell'Angelo Hospital and Santissimi Giovanni and Paolo Hospital, Mestre and Venice, Italy.

Received: 15 May 2020 Accepted: 25 September 2020 Published online: 02 October 2020

\section{References}

1. Heo Y-A, Syed YY, Keam SJ. Pegaspargase: a review in Acute Lymphoblastic Leukaemia. Drugs. 2019;79(7):767-77.

2. Hoelzer D, Bassan R, Dombret H, Fielding A, Ribera JM, Buske C. Acute lymphoblastic leukaemia in adult patients: ESMO clinical practice guidelines for diagnosis, treatment and follow-up. Ann Oncol Off J Eur Soc Med Oncol. 2016;27(suppl 5):v69-82.

3. Stock W, La M, Sanford B, Bloomfield CD, Vardiman JW, Gaynon P, et al. What determines the outcomes for adolescents and young adults with acute lymphoblastic leukemia treated on cooperative group protocols? A comparison of Children's Cancer group and Cancer and Leukemia group B studies. Blood. 2008;112(5):1646-54.

4. Müller HJ, Boos J. Use of L-asparaginase in childhood ALL. Crit Rev Oncol Hematol. 1998;28(2):97-113.

5. Pui C-H, Evans WE. A 50-year journey to cure childhood acute lymphoblastic leukemia. Semin Hematol. 2013;50(3):185-96.

6. Goekbuget N, Baumann A, Beck J, Boos J, Brueggemann M, Diedrich H, et al. PEG-Asparaginase in Adult Acute Lymphoblastic Leukemia (ALL): Efficacy and Feasibility Analysis with Increasing Dose Levels. Blood. 2008; 112(11):302. Available from. https://doi.org/10.1182/blood.V112.11.302.302.

7. Goekbuget N, Baumann A, Beck J, Brueggemann M, Diedrich H, Huettmann A, et al. PEG-Asparaginase Intensification In Adult Acute Lymphoblastic Leukemia (ALL): Significant Improvement of Outcome with Moderate Increase of Liver Toxicity In the German Multicenter Study Group for Adult ALL (GMALL) Study 07/2003. Blood. 2010;116(21):494. Available from. https:// doi.org/10.1182/blood.V116.21.494.494.

8. Toft N, Birgens H, Abrahamsson J, Griškevičius L, Hallböök H, Heyman M, et al. Results of NOPHO ALL2008 treatment for patients aged 1-45 years with acute lymphoblastic leukemia. Leukemia. 2018;32(3):606-15.

9. Avramis VI, Sencer S, Periclou AP, Sather H, Bostrom BC, Cohen $\amalg$, et al. A randomized comparison of native Escherichia coli asparaginase and polyethylene glycol conjugated asparaginase for treatment of children with newly diagnosed standard-risk acute lymphoblastic leukemia: a Children's Cancer group study. Blood. 2002;99(6):1986-94.

10. Burke MJ, Lamba JK, Pounds S, Cao X, Ghodke-Puranik Y, Lindgren BR, et al. A therapeutic trial of decitabine and vorinostat in combination with chemotherapy for relapsed/refractory acute lymphoblastic leukemia. Am J Hematol. 2014;89(9):889-95.

11. Rizzari C, Conter V, Starý J, Colombini A, Moericke A, Schrappe M. Optimizing asparaginase therapy for acute lymphoblastic leukemia. Curr Opin Oncol. 2013;25(Suppl 1):S1-9.

12. Salzer WL, Asselin B, Supko JG, Devidas M, Kaiser NA, Plourde P, et al. Erwinia asparaginase achieves therapeutic activity after pegaspargase allergy: a report from the Children's oncology group. Blood. 2013;122(4): 507-14.

13. Wang B, Relling MV, Storm MC, Woo MH, Ribeiro R, Pui C-H, et al. Evaluation of immunologic crossreaction of antiasparaginase antibodies in acute lymphoblastic leukemia (ALL) and lymphoma patients. Leukemia. 2003;17(8): 1583-8

14. Douer D, Yampolsky H, Cohen LJ, Watkins K, Levine AM, Periclou AP, et al. Pharmacodynamics and safety of intravenous pegaspargase during remission induction in adults aged 55 years or younger with newly diagnosed acute lymphoblastic leukemia. Blood. 2007;109(7):2744-50.

15. Kawedia JD, Rytting ME. Asparaginase in acute lymphoblastic leukemia. Clin Lymphoma Myeloma Leuk. 2014;14(Suppl):S14-7.
16. Aldoss I, Douer D. How I treat the toxicities of pegasparaginase in adults with acute lymphoblastic leukemia. Blood. 2020;135(13):987-95.

17. 2017 CTC for AE (CTCAE) version5. https://ctep.cancer.gov/ protocolDevelopment/electronic_applications/docs/.CTCAE_v5_Quick_ Reference_5x7pdf.

18. Patel B, Kirkwood AA, Dey A, Marks DI, McMillan AK, Menne TF, et al. Pegylated-asparaginase during induction therapy for adult acute lymphoblastic leukaemia: toxicity data from the UKALL14 trial. Leukemia. 2017;31(1):58-64.

19. Siegel SE, Advani A, Seibel N, Muffly L, Stock W, Luger S, et al. Treatment of young adults with Philadelphia-negative acute lymphoblastic leukemia and lymphoblastic lymphoma: hyper-CVAD vs. pediatric-inspired regimens. Am J Hematol. 2018;93(10):1254-66.

20. Siegel SE, Stock W, Johnson RH, Advani A, Muffly L, Douer D, et al. Pediatricinspired treatment regimens for adolescents and young adults with Philadelphia chromosome-negative Acute Lymphoblastic Leukemia: a review. JAMA Oncol. 2018;4(5):725-34.

21. Carobolante F, Chiaretti S, Skert C, Bassan R. Practical guidance for the management of acute lymphoblastic leukemia in the adolescent and young adult population. Ther Adv Hematol. 2020;11:2040620720903531.

22. Progress in treatment of ALL in adults EHA Library. Gökbuget N. 06/12/16; 136670 Topic: 3Aa B lymphoblastic leukemia/lymphoma. Available from. https://library.ehaweb.org/eha/2016/21st/136670/nicola.gkbuget.progress.in. treatment.of.all.in.adults.html?f=listing\%3D0\%2Abrowseby\%3D8\%2 Asortby\%3D1\%2Asearch\%3Dg\%C3\%B6kbuget.

23. Testi AM, Piciocchi A, D'Angiò M, Vitale A, Guarini AR, De Propris MS, et al. Italian GIMEMA 1308 protocol 802 treatment of acute lymphoblastic leukemia (ALL) in adolescents and young 803 adults (AYA): intensification of treatment based on the pediatric AIEOP ALL 8042000 protocol. Abstr Present 19th Congr Eur Hematol Assoc Milan. 2014. Haematologica. 2014; 99(S1):259.

24. Sequential Chemotherapy and Blinatumomab to Improve Minimal Residual Disease Response and Survival in Acute Lymphoblastic Leukemia (GIMEMA LAL2317). Available from https//clinicaltrials.gov/ ct2/show/NCT03367299.

25. Bassan R, Chiaretti S, Paoloni F, Audisio E, Marbello L, Borlenghi E, et al. First results of new GIMEMA trial LAL1913 for adult patients with Philadelphianegative acute lymphoblastic leukemia (Ph- ALL). HemaSphere. 2018;2(s1): 408 abstract PS919.

26. Diamond IR, Grant RC, Feldman BM, Pencharz PB, Ling SC, Moore AM, et al. Defining consensus: a systematic review recommends methodologic criteria for reporting of Delphi studies. J Clin Epidemiol. 2014;67(4):401-9.

27. Hasson F, Keeney S, McKenna H. Research guidelines for the Delphi survey technique. J Adv Nurs. 2000;32(4):1008-15.

28. Nair R, Aggarwal R, Khanna D. Methods of formal consensus in classification/diagnostic criteria and guideline development. Semin Arthritis Rheum. 2011:41(2):95-105.

29. Masetti R, Pession A. First-line treatment of acute lymphoblastic leukemia with pegasparaginase. Biologics. 2009;3:359-68.

30. Pieters R, Hunger SP, Boos J, Rizzari C, Silverman L, Baruchel A, et al. Lasparaginase treatment in acute lymphoblastic leukemia: a focus on Erwinia asparaginase. Cancer. 2011;117(2):238-49.

31. Raetz EA, Salzer WL. Tolerability and efficacy of L-asparaginase therapy in pediatric patients with acute lymphoblastic leukemia. J Pediatr Hematol Oncol. 2010:32(7):554-63.

32. Sallan SE, Gelber RD, Kimball V, Donnelly M, Cohen HJ. More is better! Update of Dana-Farber Cancer Institute/Children's hospital childhood acute lymphoblastic leukemia trials. Haematol Blood Transfus. 1990;33:459-66.

33. Huguet F, Leguay T, Raffoux E, Thomas X, Beldjord K, Delabesse E, et al. Pediatric-inspired therapy in adults with Philadelphia chromosome-negative acute lymphoblastic leukemia: the GRAALL-2003 study. J Clin Oncol Off J Am Soc Clin Oncol. 2009;27(6):911-8.

34. Storring JM, Minden MD, Kao S, Gupta V, Schuh AC, Schimmer AD, et al. Treatment of adults with BCR-ABL negative acute lymphoblastic leukaemia with a modified paediatric regimen. Br J Haematol. 2009;146(1):76-85.

35. Wetzler M, Sanford BL, Kurtzberg J, DeOliveira D, Frankel SR, Powell BL, et al. Effective asparagine depletion with pegylated asparaginase results in improved outcomes in adult acute lymphoblastic leukemia: Cancer and Leukemia group B study 9511. Blood. 2007;109(10):4164-7.

36. Christ TN, Stock W, Knoebel RW. Incidence of asparaginase-related hepatotoxicity, pancreatitis, and thrombotic events in adults with acute 
lymphoblastic leukemia treated with a pediatric-inspired regimen. J Oncol Pharm Pract Off Publ Int Soc Oncol Pharm Pract. 2018;24(4):299-308.

37. Balsat M, Hunault M, Cacheux V, Thomas X. Tolerance, compliance and efficacy of I-asparaginase during induction phase in adult Philadelphianegative acute lymphoblastic leukemia: experience of the GRAALL-2005. Haematologica. 2016;101:P166.

38. Taylor-Robinson SD. In: Kaplowitz N, DeLeve LD, editors. Drug-Induced Liver Disease, vol. £195.00. New York: Marcel Decker; 2003. p. 773. ISBN 0-82470811-3. Gut [internet]. 2003 May;52(5):773. Available from: https://www.ncbi. nlm.nih.gov/pmc/articles/PMC1773625/.

39. Zimmerman HJ. Hepatotoxicity: the adverse effects of drugs and other chemicals on the liver. 2nd ed. Philadelphia: Lippincott Williams \& Wilkins; 1999. p. 800. ISBN 0-7817-1952-6.

40. Stock W, Douer D, DeAngelo DJ, Arellano M, Advani A, Damon L, et al. Prevention and management of asparaginase/pegasparaginase-associated toxicities in adults and older adolescents: recommendations of an expert panel. Leuk Lymphoma. 2011;52(12):2237-53.

41. Zalewska-Szewczyk B, Gach A, Wyka K, Bodalski J, Młynarski W. The crossreactivity of anti-asparaginase antibodies against different $L$-asparaginase preparations. Clin Exp Med. 2009;9(2):113-6.

42. Asselin B, Rizzari C. Asparaginase pharmacokinetics and implications of therapeutic drug monitoring. Leuk Lymphoma. 2015;56(8):2273-80.

43. Tong WH, Pieters R, Kaspers GJL, te Loo DMWM, Bierings MB, van den Bos $C$, et al. A prospective study on drug monitoring of PEGasparaginase and Erwinia asparaginase and asparaginase antibodies in pediatric acute lymphoblastic leukemia. Blood. 2014;123(13):2026-33.

44. Asparaginase Activity Monitoring (AAM) in Adult Patients With Acute Lymphoblastic Leukemia (ALL) (ALL2518). Available from https//clinicaltrials. gov/ct2/show/NCT03668392.

45. Carpentieri U, Balch MT. Hyperglycemia associated with the therapeutic use of L-asparaginase: possible role of insulin receptors. J Pediatr. 1978 Nov; 93(5):775-8.

46. Howard SC, Pui C-H. Endocrine complications in pediatric patients with acute lymphoblastic leukemia. Blood Rev. 2002;16(4):225-43.

47. Blackman A, Boutin A, Shimanovsky A, Baker WJ, Forcello N. Levocarnitine and vitamin $B$ complex for the treatment of pegaspargase-induced hepatotoxicity: a case report and review of the literature. J Oncol Pharm Pract Off Publ Int Soc Oncol Pharm Pract. 2018;24(5):393-7.

48. Rausch CR, Paul S, Marx KR, Jabbour E, Pemmaraju N, Ferrajoli A, et al. Lcarnitine and vitamin $\mathrm{B}$ complex for the treatment of Pegasparaginaseinduced Hyperbilirubinemia. Clin Lymphoma Myeloma Leuk. 2018;18(5): e191-5.

49. Schulte RR, Madiwale MV, Flower A, Hochberg J, Burke MJ, McNeer JL, et al. Levocarnitine for asparaginase-induced hepatic injury: a multi-institutional case series and review of the literature. Leuk Lymphoma. 2018:59(10):2360-8.

50. Abbott LS, Deevska M, Fernandez CV, Dix D, Price VE, Wang H, et al. The impact of prophylactic fresh-frozen plasma and cryoprecipitate on the incidence of central nervous system thrombosis and hemorrhage in children with acute lymphoblastic leukemia receiving asparaginase. Blood. 2009;114(25):5146-51.

51. Orvain C, Balsat M, Tavernier E, Marolleau J-P, Pabst T, Chevallier P, et al. Thromboembolism prophylaxis in adult patients with acute lymphoblastic leukemia treated in the GRAALL-2005 study. Blood. 2020;136(3):328-38.

52. Payne JH, Vora AJ. Thrombosis and acute lymphoblastic leukaemia. Br J Haematol. 2007;138(4):430-45.

53. Caruso V, lacoviello L, Di Castelnuovo A, Storti S, Mariani G, de Gaetano G, et al. Thrombotic complications in childhood acute lymphoblastic leukemia: a meta-analysis of 17 prospective studies comprising 1752 pediatric patients. Blood. 2006;108(7):2216-22.

54. Rosendaal FR, Helmerhorst FM, Vandenbroucke JP. Oral contraceptives, hormone replacement therapy and thrombosis. Thromb Haemost. 2001; 86(1):112-23.

55. Stegeman BH, de Bastos M, Rosendaal FR, van Hylckama VA, Helmerhorst FM, Stijnen T, et al. Different combined oral contraceptives and the risk of venous thrombosis: systematic review and network meta-analysis. BMJ. 2013;347: 55298.

56. Greiner J, Schrappe M, Claviez A, Zimmermann M, Niemeyer C, Kolb R, et al. THROMBOTECT - a randomized study comparing low molecular weight heparin, antithrombin and unfractionated heparin for thromboprophylaxis during induction therapy of acute lymphoblastic leukemia in children and adolescents. Haematologica. 2019;104(4):756-65.
57. Earl M. Incidence and management of asparaginase-associated adverse events in patients with acute lymphoblastic leukemia. Clin Adv Hematol Oncol. 2009; $7(9): 600-6$

58. Kearney SL, Dahlberg SE, Levy DE, Voss SD, Sallan SE, Silverman LB. Clinical course and outcome in children with acute lymphoblastic leukemia and asparaginase-associated pancreatitis. Pediatr Blood Cancer. 2009;53(2):162-7.

59. Raja RA, Schmiegelow K, Frandsen TL. Asparaginase-associated pancreatitis in children. Br J Haematol. 2012;159(1):18-27.

60. Tong WH, Pieters R, de Groot-Kruseman HA, Hop WCJ, Boos J, Tissing WJE, et al. The toxicity of very prolonged courses of PEGasparaginase or Erwinia asparaginase in relation to asparaginase activity, with a special focus on dyslipidemia. Haematologica. 2014;99(11):1716-21.

61. Bhojwani D, Darbandi R, Pei D, Ramsey LB, Chemaitilly W, Sandlund JT, et al. Severe hypertriglyceridaemia during therapy for childhood acute lymphoblastic leukaemia. Eur J Cancer. 2014;50(15):2685-94.

62. van der Sluis IM, Vrooman LM, Pieters R, Baruchel A, Escherich G, Goulden $\mathrm{N}$, et al. Consensus expert recommendations for identification and management of asparaginase hypersensitivity and silent inactivation. Haematologica. 2016;101(3):279-85.

63. Vrooman LM, Stevenson KE, Supko JG, O'Brien J, Dahlberg SE, Asselin BL, et al. Postinduction dexamethasone and individualized dosing of Escherichia Coli L-asparaginase each improve outcome of children and adolescents with newly diagnosed acute lymphoblastic leukemia: results from a randomized study--Dana-Farber Cancer Institute ALL. J Clin Oncol Off J Am Soc Clin Oncol. 2013;31(9):1202-10.

64. Avramis VI, Panosyan EH. Pharmacokinetic/pharmacodynamic relationships of asparaginase formulations: the past, the present and recommendations for the future. Clin Pharmacokinet. 2005;44(4):367-93.

65. Schore RJ, Devidas M, Bleyer A, Reaman GH, Winick N, Loh ML, et al. Plasma asparaginase activity and asparagine depletion in acute lymphoblastic leukemia patients treated with pegaspargase on Children's oncology group AALL07P4(). Leuk Lymphoma. 2019;60(7):1740-8.

66. Lanvers-Kaminsky C, Niemann A, Eveslage M, Beck J, Köhnke T, Martin S, et al. Asparaginase activities during intensified treatment with pegylated $E$. coli asparaginase in adults with newly-diagnosed acute lymphoblastic leukemia. Leuk Lymphoma. 2020;61(1):138-45.

67. Derman BA, Streck M, Wynne J, Christ TN, Curran E, Stock W, et al. Efficacy and toxicity of reduced vs. standard dose pegylated asparaginase in adults with Philadelphia chromosome-negative acute lymphoblastic leukemia. Leuk Lymphoma. 2020;61(3):614-22.

\section{Publisher's Note}

Springer Nature remains neutral with regard to jurisdictional claims in published maps and institutional affiliations.

Ready to submit your research? Choose BMC and benefit from:

- fast, convenient online submission

- thorough peer review by experienced researchers in your field

- rapid publication on acceptance

- support for research data, including large and complex data types

- gold Open Access which fosters wider collaboration and increased citations

- maximum visibility for your research: over $100 \mathrm{M}$ website views per year

At BMC, research is always in progress.

Learn more biomedcentral.com/submissions 